\title{
The Impact of External Relationships on the Growth of Young Technology Companies
}

\section{Chris Justus}

\author{
"It is through cooperation, rather than conflict, that your") \\ greatest successes will be derived. \\ Ralph Charell \\ Author
}

\begin{abstract}
Most management teams in young technology companies are aware that their success may depend on strong relationships with external organizations. However, it may not be clear to them which types of relationships are most likely to impact their growth. This article describes the author's recent research to examine the relationship between the number and diversity of business relationships and the revenue growth of young companies. By examining data collected from 80 technology firms, and the 1943 relationships they established over a two-year period, certain types of relationships were found to have measurable impacts on growth. The article focuses on the managerial implications of these findings, which include the importance of early funding, niche identification, and building relationships with large firms.
\end{abstract}

\section{Introduction}

For young companies in particular, growth often equates to survival. Growth provides a company with more resources - primarily financial resources - that it can use to attract better employees, invest in research and development, and market and sell its products and services, all of which increase the likelihood of further growth and maturation. Accordingly, researchers have studied a wide variety of factors that impact the growth of new companies, including: founder characteristics (e.g., personality, values, skills, experience, education, behaviours, decisions), industry characteristics (e.g., market size, barriers to entry, competitive landscape, nature of buyers), and business strategy variables (e.g., strategy formulation, goals, strategic direction, entry strategy, competitive positioning, segmentation, scope, investment strategy, alliances). For further details of these factors and a proposed model of their impact on new venture performance, see Chrisman, Bauerschmidt, and Hofer (1998; http://tinyurl.com/3c2cxq8).

Among these factors, both researchers and management teams alike are increasingly recognizing the importance of a company's relationships, which include any interactions between a company and an external organization. A relationship can be a customer or supplier relationship, or a relationship in which the firms work together directly, such as a joint venture or a marketing or business partnership. It can also include financial relationships in which a firm receives financing in return for equity or other considerations. Finally, a relationship can be with a standards body or an association through which the firm associates with other related firms.

Street and Cameron (2007; http://tinyurl.com/3cdnppq) reviewed the literature related to networks, alliances, joint ventures, and ecosystems and found that researchers commonly examined how these systems work, who participates in these relationships, and how these relationships benefit the organizations that are working together. The units of analysis in the literature reviewed by Street and Cameron were individual firms, two-firm partnerships (examining who extracts the most value from the other firm), or entire networks, but the review focused on established firms and did not specifically consider the relationships of young companies. (In this article, "young" refers to a company that between two and 10 years of age. Unlike a startup, a young company is an established organization with revenue from a product or service.) 


\section{Impact of External Relationships on the Growth of Young Technology Companies} Chris Justus

Similarly, a substantial body of literature has examined how networks can assist a firm and how networks should be ignored at a firm's peril (e.g., Lechner and Dowling, 2003: http://tinyurl.com/3zxcqfl; Larson, 1991: http://tinyurl.com/3lprkq5). Networks can assist companies by helping them to establish credibility. They can fill holes in a market offering, allowing a company to focus on its core product or service, while other firms assist in other ways. Networks can help firms reach international markets that would not otherwise be easily entered. Relationships with customers can help a firm to build products that better meet that customers needs, and in turn better fit the market as a whole. Networks can also help give firms access to resources (capital, intellectual property, etc) that they would not otherwise have access to alone. Companies can work with associations or standards bodies to increase credibility, sway a standard towards a new company's technology, as well as allowing a group of firms to spread risk and rewards. Unfortunately, despite the compelling reasons why network relationships can be advantageous, the research in this area typically does not examine young companies in particular.

While many of the factors examined by studies of relationships in established firms overlap with the factors of interest for young companies (i.e., examining characteristics of the management team and the firm, as well as its strategies, systems, processes, and resources), the majority of the research has focused on established firms. This is notable because relationships may be of higher importance to young companies and young companies have limited abilities to establish and maintain relationships relative to established firms.

The author is aware of only two studies that directly examine the impact of relationships on new company growth, and even these studies offer little in the way of generalized guidance for young companies. Baum, Calabrese, and Silverman (2000; http://tinyurl.com/3rvjccn) examined startup biotechnology companies in Canada and reported on how the relationships they established positively affected revenue and research output. Their findings are specific to the biotechnology industry, which is a unique industry (the high costs associated with bringing a biotechnology product to market forces a startup to work with established players, and this symbiotic relationship has been consistent over decades), and not necessarily applicable to the North American information technology market. Lee, Lee, and Pennings (2001; http://tinyurl.com/3vupmlr) examined startup technology firms in Korea. The Korean market is unique in that the government and established banking system have a large effect on the success of a technology startup, providing financial resources and connections to promising firms. Again, this research was not necessarily applicable to the North American information technology market.

So, despite the critical role that growth plays in the early days of a company's existence and the recognition of the importance of relationships, it is surprising that this area has received so little attention in the literature. Even research into the growth factors for new ventures has generally ignored the relationships that new companies establish. As a result, there is a lack of models or explanations for why one firm succeeds while another similar firm fails, at least with respect to the role of relationships in these outcomes. Further, the literature lacks research that identifies the types of relationships that might be most beneficial to young companies. As Gulati, Lavie, and Singh (2009; http://tinyurl.com/3f5hqr2) observe: "not all relationships are equal, and ... some relationships force exclusivity or monogamy, preventing a firm from forming other relationships."

This article summarizes recent research to address this important gap in the literature as part of the author's Master's thesis in the Technology Innovation Management program (http://carleton.ca/tim) at Carleton University. The aim of the research was to better understand the importance of relationships as a growth factor for new companies and what types of relationships might be most beneficial for young information technology companies.

The structure of this article is as follows. First, an overview of the methodology will be provided. Next, the results of the research will be presented and discussed. Finally, conclusions are given, including a summary of the key implications of the research for management teams in young companies.

\section{Research Method Overview}

One of the reasons for a relative lack of research into the relationships of young companies may be the difficulties in collecting data. Most mature firms are publicly traded, and as such, their financial information is audited, and databases about these firms are available. In contrast, limited financial information is available for young companies, most of which are privately held. When researching these companies, the typical approach is to collect data through interviews or surveys, 


\section{Impact of External Relationships on the Growth of Young Technology Companies}

\section{Chris Justus}

which means that samples sizes are small and the data is subject to opinion and bias.

In this research, historical sources available on the Internet were used to collect data about Canadian information technology firms founded between 1995 and 2005. The goal was to collect sufficient objective data to determine whether the number and diversity of relationships affected the growth rate of young companies. The expectation was that the more relationships that a firm had, and the more diverse its relationships, the faster the firm would grow. This expectation was based on the assumption that young companies would be able to leverage these relationships, in effect creating value simply by creating relationships. It was also expected that a firm could over-extend itself and that firms with too many relationships would display weak growth.

Historical Branham300 lists (http://branham300.com) from 2002 to 2010 were used to identify a sample of 80 young companies and collect revenue data. Branham300 lists are yearly compilations of data about the 300 largest information technology companies in Canada and include both publicly traded and private companies. The lists include revenue data, which is either from public records, supplied by the firms, or is estimated by Branham. For each firm in the sample, three consecutive years of revenue data were used to calculate the firm's growth rate.

While the Branham 300 list features the 300 largest companies, it is important to note that the sampling criteria meant that the sample came mostly from the bottom half of the list and did not include only successful firms. The sample displayed a wide range of annualized growth rates, which varied from $345 \%$ to $-59 \%$, with 12 of 80 firms having a negative annualized growth rate (Figure 1).

Once the young companies had been indentified, historical sources on the Internet were used to gather relationship data for the two-year period before the first revenue observation from the Branham300 list. A twoyear period was chosen so that: i) more data could be gathered; ii) relationship changes could be observed; and iii) to allow time for any effect of the relationships on revenue to become apparent.

The relationship data was collected through Internet searches and the Internet Archive (http://archive.org), which is sometimes referred to as the "Wayback Machine". The Internet Archive stores historical snapshots

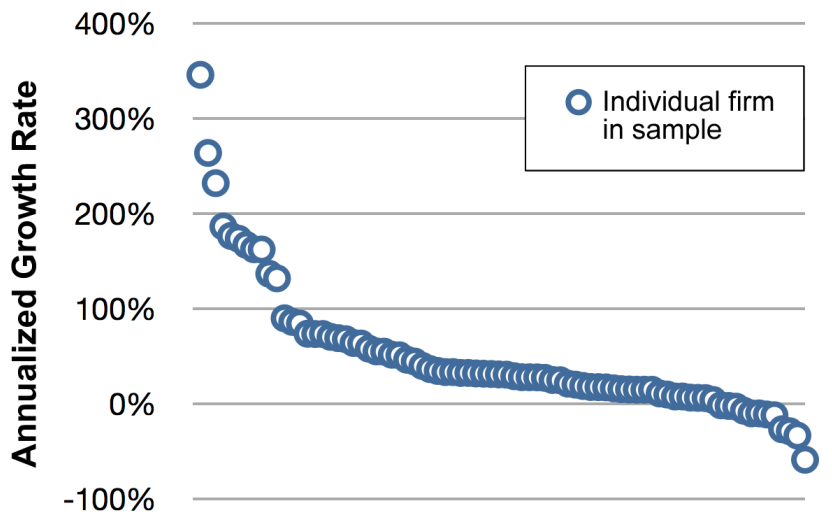

Figure 1. Annualized growth rate of the 80 young companies in this sample

of websites and currently holds over 150 billion pages, covering from 1996 to the present. By viewing historical versions of companies' website, data about their past relationships could be gathered. Through historical press releases and partner pages for 80 young companies, 1943 relationships were identified, covering a twoyear period for each firm in the sample. While these sources would not reveal all of the relationships held by these firms, they comprised a representative set of relationships that the firms self-identified as being sufficiently important to warrant the creation of a press release or inclusion on their website. Based on the data, variables were generated representing the total number of relationships and their diversity based on the types of relationships, which were categorized as follows:

- large firms

- associations, standards bodies, or industry organiza tions

- suppliers

- distributors

- customers

- financial firms

- product integration partners

- strategic relationships with another small firm

- merger/acquisition relationships

- top management team relationships

Once collected, the relationship and revenue data were compared using a stepwise regression (http://tinyurl.com/ 3oasxdh) to examine the effect of relationship type, volume, and diversity on growth over the sampled twoyear period. 


\section{Impact of External Relationships on the Growth of Young Technology Companies} Chris Justus

\section{Results and Discussion}

The results of this study identified three factors that affect the growth in revenue of a young information technology company, which translate into the following guidance for young companies:

1. Secure funding early.

2. Identify the firm's niche.

3. Increase in the number of relationships with large firms.

\section{Securing funding early}

The first variable selected by stepwise regression represented changes in relationships with financial partners. The regression model suggests that the correlation between growth rate and this term is negative. In other words, new or discarded relations with financial firms resulted in negative performance.

This finding suggests that firms should seek funding early and then limit their need for additional funding. This is counter to the findings of Baum and colleagues (2000) and Lee and colleagues (2001), which might be due to the age of firms in those studies. The mean age of firms in this study was four years; in the other studies, firms were examined from the moment they were created.

\section{Niche identification}

The second term selected by stepwise regression represented the volume and diversity of the relationships that a firm has with other firms. This variable was based on the work of Ferrier (2001; http://tinyurl.com/3byx9lz), who found that, in the area of competitive actions, the more diverse and intense actions that were taken, the better the firm did versus a competitor. It was expected that the correlations between firm growth and relationship volume and diversity would be represented by upsidedown "U" shapes. Firms with few relationships and low diversity were expected to perform poorly, while firms with moderate to high diversity and a moderate number of relationships were expected to perform best. As the number of relationships exceeded some value at which a firm could no longer maintain all relationships, performance was expected to degrade. However, the results indicated that the correlation between relationship volume and diversity was linear and negative.
These findings suggest that young firms must focus on specific niches in order to grow. Young firms that establish many diverse relationships might be unfocused and underperform relative to their more focused peers.

\section{Relationships with large firms}

The final term selected by stepwise regression is a variable representing the change in the number of relationships with large partners, which were defined as partners with over $\$ 1 \mathrm{~B}$ of revenue. Partnerships of this type typically involve changes in behaviour at the observed young firm, but little or no change in behaviour at the large partner firm. This was the only variable that was found by stepwise regression to have a positive correlation with the growth rate of the young companies in the sample. It is interesting that this term emerged in the stepwise regression, whereas close partners or partner integration did not.

These findings suggest that, when a young company is considering various relationship opportunities (either partnering with a partner its own size, an association of firms, or with a large firm), the relationship with the large firm should be considered a priority. Previous research has demonstrated that relationships with large firms lend credibility to the young company and help the young company overcome the liability of newness (e.g., Stuart, Hoang, and Hybels, 1999: http://tinyurl.com/ 3rtutgp; Gulati and Higgins, 2003: http://tinyurl.com/3aw5lm2).

\section{Other findings}

Also of interest are the relationships variables that did not show a statistically significant effect on the growth of young companies:

1. Mergers and acquisitions. These results are consistent with Bhidé (2000; http://tinyurl.com/43hq98s) who found no significant difference in organic growth versus growth by mergers and acquisitions.

2. Distribution partnerships. Despite an expectation that young firms that created distribution networks, or business models that facilitated partners for broad distribution of a product, would be associated with higher growth, this was not supported by the stepwise regression analysis.

3. Supplier partnerships. The expectation had been that a young firm that wanted to rapidly reach a market would call upon supplier relationships to deliver non- 


\section{Impact of External Relationships on the Growth of Young Technology Companies}

\section{Chris Justus}

core technologies to a product offering, and so a firm with a high number of supplier partnerships was expected to associated with high growth. However, the results did support this expectation, and in fact showed weak support for the opposite effect.

4. Close partnerships. Working with close partners might allow equals or near equals with varying experience and markets to work together to improve their performance versus their competition. However, this variable was not found to have a statistically significant effect in the stepwise regression model.

5. Total number of relationships. Companies have a limited amount of resources available to them. Even if relationships are generally beneficial, trying to create and support too many relationships might exceed the capabilities of the firm. It was expected that the relationship might follow an arc in which firms benefit from a large number of relationships, but observe decreasing gains past a certain point. The stepwise regression included quadratic terms, which would have revealed this effect, but it was not found to be statistically significant.

6. Standards and associations. Baum et al. (2000) found that firms that joined associations in the biotechnology industry were negatively correlated with performance. They posit that this might be due to the founders trying to make up for personal and firm weaknesses by joining these organizations. If a person were to consider standards and associations with a network view, in which firms assist each other, it would be expected that these types of relationships would be beneficial. However, in this study, this variable was not found to be statistically significant in the stepwise regression.

7. Top management teams. As new members are introduced to the management team, they might bring with them their past relationships (and the potential benefits to growth that they represent). However, it is difficult to measure the effectiveness of an individual leader with the method used here to collect information about relationships, and as such it was not unexpected that this variable was not found to be important in the analysis.

\section{Conclusions}

Young companies must grow to survive. Companies traditionally create business plans outlining their business model and how they will acquire customers. Few young companies use a strategic mindset to consider their relationships with other companies. However, relationships are a resource that can be planned, monitored, and measured just like any other. Young companies have limited resources to create and maintain relationships and should therefore consider whether a particular relationship will provide value to the company. The results of this research provide guidance to management teams of young companies by highlighting the importance of three activities: i) securing funding early; ii) identifying the firm's niche; and iii) building relationships with large firms.

\section{About the Author}

Chris Justus is a software architect at bitHeads in Ottawa, Canada. He recently completed his Master's degree in the Technology Innovation Management program at Carleton University with a thesis entitled "Relationships of young information technology companies and growth in revenue." He also holds a Bachelor of Mathematics from the University of Waterloo. Chris has over 20 years of experience in the technology space and has cofounded three information technology companies, including one of the largest independent ISPs in Canada and an information technology staffing and software company.

Citation: Justus, C. 2011. The Impact of External

Relationships on the Growth of Young Technology

Companies. Technology Innovation Management

Review. November 2011: 26-30. 